\title{
Sexualidade, prazeres e vulnerabilidade: implicações educativas
}

\author{
Sexuality, pleasures and vulnerabilities: \\ educational implications
}

\author{
Dagmar E. Estermann Meyer ${ }^{1}$ \\ Carin Klein ${ }^{2}$ \\ Sandra dos Santos Andrade 3
}

\section{RESUMO}

Nas culturas ocidentais em que vivemos, de forma muito mais intensa e explícita do que em outras épocas, o amor e a sexualidade têm sido significados como dimensões indissociáveis da vida humana. A sua realização prazerosa tem sido apresentada não apenas como um direito de todos os seres humanos, mas como um imperativo ao qual todos/as estamos submetidos e a partir do qual somos valorados, classificados e posicionados como mais ou menos bem-sucedidos e saudáveis. Nesse sentido, é importante destacar toda uma discursividade que reitera, todos os dias, que ser feliz envolve, dentre outras coisas, o trabalho, o amor e a vivência plena da sexualidade; e que alguns dos ingredientes importantes para garantir a felicidade e o prazer, nesses domínios, seriam, justamente,

\footnotetext{
1 Doutora em Educação. Professora Associada na Faculdade de Educação da Universidade Federal do Rio Grande do Sul. Pesquisadora do CNPq. Membro do Grupo de Estudos de Educação e Relações de Gênero (GEERGE). dagmarmeyer@yahoo.com.br.

2 Doutoranda em Educação pela Universidade Federal do Rio Grande do Sul. Orientadora Educacional na Rede Municipal de Ensino de Canoas. Membro do Grupo de Estudos de Educação e Relações de Gênero (GEERGE). carink@terra.com.br.

3 Doutoranda em Educação pela Universidade Federal do Rio Grande do Sul. Membro do Grupo de Estudos de Educação e Relações de Gênero (GEERGE). santosa@hotmail.com.
} 
"sair da rotina", "inovar", "experimentar sensações novas" - é só dar uma folheada em livros de auto-ajuda, em revistas e nos vários programas de TV direcionados para o tema e voltados, de forma intensa, para os/as jovens. Tomando como referência esse contexto cultural e ancorando-se em vertentes dos estudos de gênero e culturais pós-estruturalistas, o presente artigo sinaliza para os desafios que se colocam para educadores e educadoras que se dispõem a trabalhar temas vinculados a gênero e sexualidade, na escola, na ótica da vulnerabilidade.

Palavras-chave: Educação em saúde na escola; Gênero e sexualidade; vulnerabilidade

\begin{abstract}
In the western cultures we live, more explicit and acutely than in other times, love and sexuality has been signified as inseparable dimensions of human life. Their pleasurable realization has been presented not only as a right of all human beings but as an imperative under all of us are submitted. We are valuated, classified and ranked as more or less wealthy and healthy through these imperatives. In this regard, it is important to detail a discourse that reiterates, every day, that being happy involves, among other things, work, love and complete realization of happiness. Some of the most important ingredients to assure happiness and pleasure in these domains were precisely "escaping from routine", "innovating", "experimenting new sensations" - take a look in self-help books, magazines and TV programs about this thematic, especially those addressed to youth. Taking this cultural context as reference, under the perspectives of post-structuralist cultural studies and gender studies, this paper points to the challenges that are presented to educators, especially to those who (at school) show themselves willing to work with themes related to gender and sexuality under the point of view of vulnerability.
\end{abstract}

Keywords: Health Education in School; Gender and Sexuality; Vulnerability. 


\section{O PRAZER COMO CONQUISTA E COMO IMPERATIVO DA CULTURA CONTEMPORÂNEA}

Nas culturas em que vivemos - e hoje talvez de forma muito mais intensa e explícita do que em outras épocas -, o amor e a sexualidade têm sido significados como dimensões indissociáveis da vida humana. Para além disso, sua realização prazerosa nos tem sido apresentada não apenas como um direito de todos os seres humanos, mas como um "imperativo" ao qual todos/as estamos submetidos e a partir do qual somos valorados/as, classificados/as e posicionados/as como mais ou menos bem-sucedidos e saudáveis. Basta que nos recordemos, por exemplo, de inquéritos sobre tipos e freqüência de relações sexuais que buscam caracterizar "a vida sexual do brasileiro", ou da criação de datas como o Dia Internacional do Orgasmo - comemorado em 31 de julho -, ou, ainda, de pesquisas que buscam descrever semelhanças e diferenças entre os modos pelos quais mulheres e homens vivem sua sexualidade e os sentidos que atribuem às suas práticas sexuais, dentre outras coisas.

Nessa cultura, de forma muito ampla, o prazer, a felicidade e a saúde, por exemplo, tornaram-se imperativos, sendo o amor e a sexualidade definidos como ingredientes indispensáveis para que esse prazer, essa felicidade e essa saúde se realizem. E a vivência desse prazer, muito freqüentemente, está associada à disposição e à capacidade de enfrentar e de correr determinados riscos, que atualizam uma relação que, historicamente, se faz entre prazer e perigo.

Assim, é importante destacar toda uma discursividade que reitera, todos os dias e em múltiplos artefatos da cultura, que ser feliz envolve, dentre outras coisas, ser feliz no trabalho, no amor e na vivência plena de sua sexualidade; e que um dos elementos importantes para garantir a felicidade e o prazer, nesses domínios, é "sair da rotina", "inovar", “experimentar sensações novas", o que é apresentado como um ingrediente de sucesso tanto para a inserção no mundo do trabalho quanto, sobretudo, 
para a sobrevida das relações amorosas e sexuais - é só prestar atenção nos conselhos dos/as sexólogos/as ou dar uma folheada em livros de autoajuda e em revistas como Claudia, Capricho, Nova, Men's Health, Playboy, além dos vários programas de TV direcionados para o tema.

Nesse contexto, sexualidade também tem sido entendida e descrita de formas bastante distintas e conflituosas: por um lado, a abordagem da sexualidade como sendo uma produção da cultura e não um instinto biologicamente determinado vem tendo uma importante penetração nas áreas da educação e da saúde e, ao mesmo tempo, a compreensão de que sexualidade envolve mais do que sexo genital voltado para a reprodução da espécie, poucas vezes, foi tão naturalizada como sendo um fundamento da psique e da personalidade humana, como hoje. E Guacira Louro (1999), Maria Andréa Loyola (2003) e Jefrey Weeks (1999), de diferentes lugares e com diferentes motivações, ajudam-nos a entender um pouco desses processos.

Maria Andréa Loyola (2003) chama atenção para o fato de que, historicamente, as sociedades distinguiram formas e situações nas quais a reprodução era admitida e desejada daquelas em que o exercício da sexualidade não deveria levar à procriação. Essas diferentes sociedades instituíram, então, mecanismos e estratégias para educar, promover e controlar os sujeitos e as diversas formas pelas quais a sexualidade poderia se manifestar e ser exercitada. No Ocidente, isso se traduziu em mecanismos de naturalização da heterossexualidade e na reprodução como função primordial das relações de conjugalidade monogâmica que aí se legitimaram, sobretudo, a partir do século XVIII. A autora faz referência a duas formas históricas de dissociação entre sexualidade reprodutiva e não reprodutiva, e ambas são intensivamente organizadas pelas relações de gênero então vigentes. Enfatizamos isso porque aqui reside uma das grandes mudanças a que assistimos a partir da segunda metade do século XX. 
Uma delas está vinculada às formas de organização das sociedades hierárquicas e de classe, nas quais a sexualidade reprodutiva estava reservada para as esposas e a sexualidade não reprodutiva, como lugar de exercício de erotismo e de prazer, para os homens em sua relação com cortesãs e/ou prostitutas, numa equação em que se colocam, de um lado, a procriação e, de outro, o desejo e o erotismo. Efeitos desse discurso ainda continuam presentes na construção de determinadas formas de viver a masculinidade e a sexualidade heterossexual, por exemplo, na referência que alguns grupos de homens fazem, ainda hoje, ao fato de que determinadas práticas sexuais não podem ser realizadas com suas mulheres, apenas com amantes ou prostitutas. Nesse contexto histórico, produz-se também uma representação de que a sexualidade feminina é passiva, dirigida ao prazer dos homens e que o prazer sexual não só não é um componente necessário, mas é um componente dispensável para a procriação e, portanto, para a vivência da sexualidade no casamento - em contraposição a um outro entendimento, anterior, em que o orgasmo feminino era representado como sendo um componente indispensável para que a concepção ocorresse (Muchembled, 2007).

Outra forma de dissociação entre sexualidade e reprodução ocorreu, segundo Loyola (2003), com a crescente diferenciação da vida humana em fases etárias, que teriam características e necessidades distintas. Nesse contexto, a puberdade, que antecederia a vida adulta propriamente dita, poderia ser dedicada à vivência de uma "sexualidade mais livre" e não procriativa, um pressuposto também válido apenas para os homens em sua relação com prostitutas ou amantes, uma vez que se esperava que as "moças de bem", destinadas ao casamento, permanecessem virgens. $\mathrm{O}$ período adulto caracterizaria uma sexualidade conjugal com fins reprodutivos para homens e mulheres, com a possibilidade do exercício da sexualidade associada ao prazer para os homens, nas relações extraconjugais. 
Guacira Louro (1999), recorrendo aos Estudos Feministas e às suas próprias lembranças acerca do tornar-se mulher, discute algumas das importantes mudanças que foram acontecendo, sobretudo a partir da segunda metade do século XX, nas possibilidades de vivência da sexualidade pelas mulheres, nas sociedades ocidentais, no contexto de um conjunto de transformações tanto tecnológicas quanto políticas. Essas transformações foram decorrentes, também, das lutas de movimentos sociais que se articularam para questionar as diferenças e as desigualdades sociais impostas às mulheres, aos grupos não brancos, aos gays e lésbicas, por exemplo, e que se intensificaram nessas sociedades a partir de maio de 1968.

Vamos nos referir, aqui, apenas a algumas dessas transformações, começando com a "invenção" da pílula anticoncepcional, que possibilitou, pela primeira vez, que alguns grupos de mulheres assumissem um controle mais direto e mais seguro sobre o seu processo reprodutivo e pudessem, portanto, usufruir dos prazeres do sexo sem o risco de engravidarem. No que se refere ao exercício da sexualidade, sobretudo quando tomamos como referência as culturas urbanas escolarizadas, a segunda metade do século XX possibilitou, também, às jovens e às mulheres adultas, dentro e fora do casamento, que vivessem o sexo por prazer, algo antes só reservado aos homens. Além disso, vivemos nos últimos 30 anos um processo importante de desmedicalização de determinadas práticas sexuais, dentre as quais se inscrevem a felação e a sodomia, hoje descritas simplesmente como sexo oral e sexo anal, que têm sido amplamente debatidas, apresentadas e até mesmo recomendadas pelos sexólogos, como formas integrantes do "exercício prazeroso" da chamada "sexualidade normal" - esta, sim, ainda significada como heterossexualidade. E é importante relembrar que a homossexualidade, até os anos 1980 do século XX, ainda era classificada como doença no Código Internacional de Doenças (CID). 
Em que pesem todos os problemas relativos às desigualdades sociais ainda enfrentados em maior ou menor grau, por diferentes grupos de mulheres (e eles continuam sendo muitos), é possível, portanto, enfatizar algumas positividades deste tempo em que estamos vivendo. Assim, não podemos deixar de reconhecer que, nas sociedades ocidentais, incluindo-se aí o Brasil, a situação das mulheres, quando falamos delas genericamente, mudou muito ao longo do século passado. Mais de 40\% da população economicamente ativa, no Brasil, hoje, é constituída por mulheres, e elas estão presentes, em maior ou menor número, em todas as atividades e profissões. Isso não significou uma divisão mais equitativa das tarefas domésticas e das que envolvem os cuidados com os filhos, mas pequenas mudanças estão ocorrendo, também aí, entre a população mais jovem. As mulheres também ainda ganham, em média, de 30 a 40\% menos do que os homens para o desempenho das mesmas atividades, mesmo quando são mais escolarizadas; mas essa diferença já foi muito maior. Não se pode deixar de referir que quase 100\% das mulheres brasileiras adentraram o século XX analfabetas e que hoje elas têm um grau de escolaridade média maior do que o dos homens e que as meninas e mulheres permanecem mais tempo na escola e reprovam menos do que eles dentro dela.

Como resultados da organização da sociedade civil e dos movimentos sociais de mulheres, temos, hoje, um conjunto de leis trabalhistas, civis e criminais que, pelo menos no plano formal (uma vez que algumas delas ainda estão longe de funcionar efetivamente de forma a afetar concretamente a vida de todos os segmentos sociais), garantem acesso e permanência ao trabalho, direito à pensão e propriedades, em casos de separação, direitos iguais nas uniões estáveis, acesso à justiça em casos de violência doméstica e sexual, à qual elas continuam, sim, muito expostas. E, no que se refere ao exercício da sexualidade, sobretudo quando tomamos como referência as culturas urbanas escolarizadas, a segunda metade do século XX possibilitou, também às jovens e às 
mulheres adultas, dentro e fora do casamento, que rompessem as fronteiras entre procriação e sexo por prazer, algo antes só reservado aos homens. E isso é algo que, para as mulheres, se deu nos últimos 50 anos - um tempo bastante curto quando pensamos em termos históricos!

É claro que precisamos matizar tudo isso, considerando que essas coisas impactam de forma muito diferenciada a vida de diferentes grupos de mulheres, que os marcadores de classe social e de raça/etnia introduzem clivagens importantes para o acesso e o exercício desses direitos, que muitas mulheres brasileiras continuam morrendo de parto e em função da realização de abortos clandestinos, continuam tendo mais filhos do que gostariam, sobrevivem de trabalhos informais que não thes dão acesso aos direitos trabalhistas, continuam expostas a violências de gênero de todos os tipos e, hoje, constituem o segmento da população brasileira em que mais cresce a infecção pelo HIV.

Com essa argumentação, pretendemos explicitar que trabalhamos com perspectivas teóricas que assumem o pressuposto de que a relação entre amor, reprodução humana, desejo e sexualidade não é entendida sempre da mesma forma e que ela se manifesta de diferentes modos, em tempos e lugares diversos. E isso implica aceitar a idéia de que cada cultura estabelece, em diferentes tempos, quais são as formas aceitáveis e permitidas de se obter prazer sexual, a quem esse prazer está facultado e o que ou quem pode ser colocado como foco de nossos desejos eróticos e afetivos "normais". E é essa perspectiva que nos permite dimensionar o quanto a relação entre reprodução, sexualidade e prazer foi se modificando, no último século, nas culturas ocidentais, de forma que podemos, hoje, não apenas pensar em uma sexualidade direcionada à reprodução e uma sexualidade direcionada para o prazer, tanto para homens e entre homens, quanto para mulheres e entre mulheres, mas podemos, também, admitir a possibilidade de formas de reprodução humana que prescindem de sexo genital heterossexual para serem levadas 
a termo. Além disso, podemos não só pensar, mas viver, legalmente, relações amorosas e sexuais com parceiros do mesmo sexo, sem abrir mão da maternidade ou da paternidade por isso.

A epidemia do HIV/AIDS também teve um impacto importante nesse contexto cultural que vimos descrevendo, sobretudo no que se refere à visibilização das práticas homossexuais como formas legítimas e amplamente disseminadas de viver a sexualidade. Mas ela também produziu uma mobilização social intensa e de fôlego, que é responsável por muito do que vemos proposto e implementado em políticas públicas de prevenção ao HIV/AIDS, no mundo, hoje; além disso, ela impactou profundamente as formas de produção de conhecimento sobre sexualidade, em saúde, porque explicitou as insuficiências da ciência biomédica para dar conta dos desafios que se colocavam. Produziu-se, em função disso, uma das mais consistentes articulações contemporâneas entre ciências biomédicas e ciências sociais e humanas e, de forma particular, evidenciou-se que não dava para pensar a prevenção ao HIV sem conhecer, problematizar e interferir nas relações de gênero e sexuais vigentes nas diferentes culturas.

A epidemia ainda possibilitou a emergência do conceito de "sexo seguro", que até hoje é uma ponta de lança importantíssima para o confronto com as posições conservadoras que pregam a castidade, a abstinência e a monogamia como melhor forma de prevenção às DSTs e ao HIV/AIDS; a epidemia ainda "colocou na mesa" das salas de aula, dos serviços de saúde e das famílias, sobretudo das de classe média católica, o tema da sexualidade e a necessidade de falar dela. E, por fim, foi o esforço de fazer frente à epidemia e de contestar os conceitos de grupos de risco e comportamentos de risco (ainda atuantes no contexto da cultura e, sobretudo, da saúde e da educação) que o quadro referencial da vulnerabilidade adentra o campo da saúde e tem sido incorporado, cada vez mais, a outros campos, como o da educação. 
A discussão que vimos fazendo remete-nos, pois, a uma definição particular do que seja sexualidade, entendida aqui como as diferentes formas através da quais homens e mulheres vivem seus desejos e seus prazeres corporais em sentido amplo, com parceiros/as do sexo oposto, com parceiros/as do mesmo sexo, com parceiros/as de ambos os sexos, sem parceiros/as, com parceiros/as virtuais, com parceiros/as inanimados, dentre outras possibilidades (Louro, 1999). E, além disso, essa discussão coloca algumas questões e desafios importantes para professores e professoras comprometidos com processos de ensinoaprendizagem que envolvem o tema da sexualidade.

Por exemplo, se considerarmos a discussão feita sobre a centralidade do prazer na cultura contemporânea, sobre a relação indissociável que se estabelece, aí, entre sexualidade e prazer, e a reiteração de que um dos elementos importantes para garantir a sobrevida das relações amorosas e sexuais entre mulheres e homens, entre mulheres e entre homens, nesses domínios, é "sair da rotina”, "inovar”, "experimentar sensações novas”, é preciso dar-se conta de que essas relações são muito pouco problematizadas e trabalhadas no contexto das práticas chamadas de educação sexual que, nas escolas, procuram fazer valer as recomendações dos Parâmetros Curriculares Nacionais. E quando o são, isso é feito com um tom moralista e prescritivo que explora muito pouco as implicações disso sobre as escolhas (ou falta de escolhas) das crianças e jovens com os quais trabalhamos. O que se enfatiza, todo o tempo, é a relação entre sexualidade e perigo, entre sexualidade e doença, entre sexualidade e pecado ou culpa, e a única solução que apresentamos a eles/as, em tom normativo e categórico, é a mesma desde que a infecção ao HIV/AIDS se tornou um problema de saúde pública: "Só faça sexo com a 'pessoa certa', no 'momento certo' e, independentemente de que seja com a 'pessoa certa' ou não, use preservativo, sempre, em todas as suas relações sexuais (genitais, anais e orais)". 
Como essa fixidez do conteúdo que atribuímos à noção de "sexo seguro" articula-se com aquele discurso mais amplo da cultura que, crescentemente, associa o prazer da sexualidade às saídas de rotina e às novas experimentações? E o que e como crianças, jovens e adultos aprendem sobre sexualidade e prazer em práticas educativas que reiteram a doença, o perigo e a culpa como conseqüências mais imediatas de seu exercício? O que significam noções como "momento certo" e "pessoa certa", exaustivamente repetidas por nós, sobretudo nas escolas, nos diferentes contextos culturais? Essa ênfase na relação da sexualidade com o perigo, a doença e a culpa, e o concomitante silêncio acerca da relação entre sexualidade e prazer poderia ser considerada como um elemento produtor de vulnerabilidade?

\section{SEXUALIDADE NA ESCOLA:}

\section{CONTRIBUIÇÕES DO CONCEITO DE VULNERABILIDADE}

Ao entendermos a instituição escolar como uma instância envolvida na produção de identidades sexuais e de gênero, bem como com a validação de determinadas formas de viver as masculinidades, as feminilidades e as sexualidades, torna-se importante focalizarmos os processos escolares envolvidos com a naturalização de diferenças e desigualdades sociais, nesses domínios. Podemos pensar que o "natural", no caso de homens e mulheres, se refere às características, atributos, funções, comportamentos e sentimentos considerados inerentes, comuns e universais, tomando dados biológicos como referência dessas construções. Certamente, essa compreensão de "natural", muitas vezes compartilhada na escola, exclui o caráter de construção das identidades sociais, da multiplicidade, da provisoriedade e da contingência do humano, bem como dos aspectos históricos, sociais, culturais e políticos que envolvem a produção dos discursos em educação. Guacira Louro (1997) sugere que comecemos, enquanto educadoras/es, por desconfiar 
de tudo o que nos é dado como natural, voltando nosso olhar para todas as práticas cotidianas em que nos envolvemos e nas quais se envolvem os/as alunos/as. Pois são "as práticas rotineiras e comuns, os gestos e as palavras banalizados que precisam se tornar alvo de atenção renovada, de questionamento e, em especial, de desconfiança” (Louro, 1997, p. 63). Por exemplo, é natural que homens sintam mais desejo do que as mulheres? Que os jovens homens tenham mais dificuldade em refrear seus impulsos sexuais? Que as meninas sejam "naturalmente" mais dóceis e submissas que os meninos? E que a submissão feminina (ou a dominação masculina) seja a maior razão da não-adoção da camisinha na relação sexual?

Sabemos que discursos desse tipo não são produzidos e nem circulam exclusivamente na escola, sendo produtos, também, de outras áreas de conhecimento e informação; e eles são, continuamente, reapresentados e re-atualizados pela ciência, nas diferentes mídias, nas tecnologias, no senso comum etc. E é exatamente por isso que eles estão tão imbricados com a organização das relações sociais (de gênero e de sexualidade) e a produção de subjetividades. Ou seja, esses diferentes discursos produzidos e veiculados em nossa cultura, e que atravessam também a escola, contribuem para produzir modos de ser e de viver a sexualidade.

De maneira geral, as práticas pedagógicas escolares e culturais posicionam determinadas identidades e práticas como sendo mais "naturais" do que outras, e, nesse sentido, ser menino ou menina, homem ou mulher, pai ou mãe, por exemplo, passa a ser instituído a partir de discursividades implicadas com a construção de fronteiras, agrupamentos e especificidades que marcam e delimitam quem pertence e quem não pertence à determinada norma ou padrão. Pautados nessas normas aceitas socialmente como ideais ou mais adequadas é que os currículos escolares, bem como os materiais didáticos e os processos avaliativos que os constituem, organizam toda a dinâmica escolar. O currículo é entendido, 
aqui, como o locus privilegiado para a produção e reprodução das diferenças, não só de gênero e de sexualidade, como também de raça, classe, geração, religião. Isso implica "desconfiar" dos (e questionar os) modos como ensinamos, dos conteúdos que selecionamos e que validamos, daquilo que incluímos e/ou excluímos do planejamento, da decoração das salas de aula, da escolha dos livros didáticos e, até mesmo, das teorizações que orientam nossas reflexões pedagógicas.

E para que ocorra uma re-discussão dos currículos que temos, talvez se torne importante analisar as possibilidades e finalidades de determinados conhecimentos, informações, histórias, brincadeiras e jogos vivenciados no espaço escolar e indagar: O que eles ensinam? Que significados, comportamentos e pertencimentos produzem? E será que, como professores/as, podemos incluir essas discussões em nosso planejamento e na articulação com as diferentes áreas do conhecimento? Por que e como analisar e discutir com os/as jovens estudantes questões sobre sexualidade, corpo, prazer, saúde e vulnerabilidades? E talvez devêssemos nos perguntar, ainda: Como gênero e sexualidade articulamse na cultura para produzir determinadas formas de viver os desejos e os prazeres corporais, para umas e para outros?

De modo geral, a sexualidade continua sendo tematizada, nas escolas, sob o enfoque do risco, seguindo a tradicional hegemonia do referencial médico, e as práticas educativas que enfocam a promoção da saúde sexual e a prevenção de gravidez e de doenças nessa esfera têm sido orientadas por um viés individualista. As abordagens pedagógicas que as sustentam continuam centradas na conscientização individual do risco e na necessidade de negociar o sexo seguro com o parceiro, sem levar em conta as condições sociais e estruturais que definem as posições de poder (e de hierarquia) no âmbito das práticas de gênero e de sexualidade e sem problematizar as formas pelas quais as diferentes culturas representam as masculinidades e as feminilidades hegemônicas, o amor e o prazer sexual, 
viabilizando ou não possibilidades concretas para essas "negociações". Cabe, portanto, investir mais em uma discussão teórica que problematize esses enfoques; o que vamos fazer, aqui, a partir do conceito de vulnerabilidade. Para nós, isso parece importante, tendo em vista que o termo tem sido crescentemente incorporado ao vocabulário político nas áreas da saúde e da educação de nossa época.

A construção do quadro conceitual da vulnerabilidade no campo da saúde é relativamente recente e está estreitamente relacionada ao esforço de superação das práticas preventivas de saúde apoiadas no conceito de risco, sobretudo no contexto da epidemia do HIV/AIDS. Risco, historicamente, conformou-se como um instrumento preditivo de quantificação das possibilidades de indivíduos ou populações virem a sofrer determinados agravos, em sentido lato, a partir da identificação de associações entre eventos ou condições insalubres, do ponto de vista biológico, social ou moral, e outros eventos e condições saudáveis, do mesmo ponto de vista, e que seriam causalmente relacionáveis (Ayres et al., 2003, p. 127). Vulnerabilidade, por sua vez, é um conceito muito mais amplo e complexo, que implica "o movimento de considerar a chance de exposição das pessoas ao adoecimento [e a outros agravos sociais] como a resultante de um conjunto de aspectos não apenas individuais, mas também coletivos [e] contextuais" (Ibidem, p. 123); esses aspectos estão relacionados com a sua maior suscetibilidade a esses agravos e, concomitantemente, com sua maior ou menor disponibilidade de recursos de proteção.

Delor e Hubert (2000) consideram que vulnerabilidade é uma forma de análise que busca compreender o que chamam de "distribuição desigual do risco". Ou seja, esse tipo de análise e avaliação demanda a compreensão de processos de diferenciação social que se materializam como desvantagens de diversos tipos e ajuda a compreender melhor porque e como determinados grupos e indivíduos se tornam, em 
determinado tempo e contexto, mais suscetíveis a determinados agravos e problemas do que outros. É indispensável, então, questionar, conhecer e analisar as situações de vulnerabilidade a que estão expostos os/as estudantes, principalmente das escolas públicas, para que se possa atuar em parceria com outras instituições, a fim de reduzir, através da educação, as possibilidades de se tornar vulnerável a alguém, ou a alguma coisa ou situação.

As diferentes situações de vulnerabilidade dos sujeitos (individuais e/ou coletivos) podem ser particularizadas, segundo Ayres et al. (2003), pelo re-conhecimento de três componentes interligados - o individual, o social e o programático ou institucional, os quais remetem às seguintes questões de ordem prática: Vulnerabilidade de quem? Vulnerabilidade a quê? Vulnerabilidade em que circunstâncias ou condições? Essas são as perguntas que podemos fazer, enquanto professores/as, para analisar as condições de vida de crianças e jovens com os quais trabalhamos, no sentido de identificar vulnerabilidades que experimentam ou que estão sujeitos a vivenciar.

No plano individual, considera-se que a vulnerabilidade a algum agravo está relacionada, basicamente, aos comportamentos que criam oportunidades para que as pessoas venham a contrair doenças ou a viver em determinadas condições, e esses comportamentos são relacionados tanto com condições objetivas do ambiente quanto com condições culturais e sociais em que os comportamentos ocorrem, bem como com o grau de consciência que essas pessoas e grupos têm sobre tais comportamentos, e ao efetivo poder que podem exercer para transformálos, sendo a escola uma das instituições que pode instrumentalizar os/as estudantes a lidar com tais situações.

O componente social da vulnerabilidade envolve o acesso às informações, as possibilidades de compreendê-las e o poder de incorporálas a mudanças práticas na vida cotidiana. Essas condições estão 
diretamente associadas ao acesso a recursos materiais, a instituições sociais como escola e serviços de saúde, ao poder de influenciar decisões políticas, à possibilidade de enfrentar barreiras culturais, dentre outras. $\mathrm{O}$ componente institucional ou programático da vulnerabilidade envolve o grau e a qualidade de compromisso, recursos, gerência e monitoramento de programas nacionais, regionais ou locais de prevenção e cuidado, que são importantes para identificar necessidades, canalizar os recursos sociais existentes e otimizar seu uso.

Articulados entre si, os três componentes constitutivos do quadro conceitual da vulnerabilidade consideram que as pessoas não são, em si, vulneráveis, mas podem estar vulneráveis a alguns agravos e não a outros, sob determinadas condições, em diferentes momentos de suas vidas. E, nessa direção, pensamos que deveríamos perguntar-nos, mais enfaticamente: Até que ponto os conhecimentos, políticas e programas de educação contribuem para produzir, aumentar ou manter a vulnerabilidade que se propõem a modificar ou romper? Como a escola, através de seus processos formais de produção de conhecimento, colabora para produzir e desenvolver potencialidades nos sujeitos para lidar com suas situações de vulnerabilidade?

Ao dar ênfase à compreensão de que meninos/homens estão "naturalmente" relacionados a atividades que exploram o uso da razão, a atividades de gerenciamento e comando, à agressividade e à competitividade e as meninas/mulheres ao desenvolvimento da docilidade, sensibilidade, cooperação, passividade, atividades de proteção e cuidado, a escola acaba persistindo na (e contribuindo para a) produção de comportamentos que seguem instituindo diferenças e desigualdades de gênero. Conseqüentemente, esses ensinamentos incidem sobre as nossas formas de viver a sexualidade, os nossos prazeres e, sobretudo, as formas de nos relacionarmos com o cuidado e a promoção da saúde, reduzindo ou aprofundando situações de vulnerabilidade. 
A escola contribui largamente para essa naturalização dos comportamentos e vulnerabilização dos sujeitos quando não revê o seu currículo, quando mantém a fixidez e a rigidez dos programas escolares, quando não se dispõe a uma problematização ampla e complexa das desigualdades que vão se construindo em torno das diferenças de gênero, sexualidade, raça e classe. Assim, o que pode, ou não, ser dito na escola passa a constituir e atravessar as nossas práticas e o que pensamos. Em função disso, "temos de estar atentos/as, sobretudo, para nossa linguagem, procurando perceber o sexismo, o racismo e o etnocentrismo que ela freqüentemente carrega e institui” (Louro, 1997, p. 64).

A escola, através de seus conhecimentos e práticas, parece ainda estar regulada a partir de uma ênfase marcada pelo campo das ciências biológicas e naturais, mostrando a sua completa desarticulação com os interesses e as lutas dos diferentes grupos e movimentos sociais. Desse modo, semelhanças, diferenças e desigualdades em relação a gênero e sexualidade e que envolvem os processos de promoção da saúde ainda vêm sendo determinadas e justificadas por pressupostos da biologia elegendo o corpo (e o seu funcionamento) como fundamento e substrato principal de suas explicações.

Contemporaneamente, entendemos que as discussões que abarcam a construção de gênero, sexualidade, prazer, corpo e saúde envolvem dimensões políticas e sociais que, por sua vez, estão implicadas com a escola e com a função docente, sobretudo na direção de perceber que os conhecimentos escolares estão imbricados com a produção e atribuição das diferenças de gênero, da educação que institui a heterossexualidade como norma e com a exclusão ou silenciamento dos prazeres e vivências juvenis. Não problematizar, não oferecer espaço para discussão, não apresentar as diversas possibilidades de se pensar sobre questões que instigam e colocam os/as estudantes sob diferentes riscos como: HIV/AIDS, sexualidade, sexo seguro, prazer, gravidez indesejada, 
é contribuir para criar ou aprofundar as múltiplas situações de vulnerabilidade a que estão expostos os/as jovens. Educar, hoje, também inclui pensar na perspectiva da redução de danos, da diminuição de agravos e evitar ou diminuir a exposição a riscos.

\section{ALGUMAS CONSIDERAÇÕES...}

Frente aos atuais desafios do campo da educação em saúde, parece não haver mais lugar para adotarmos "modelos" educacionais corretos, acabados e inquestionáveis. Desde essa perspectiva, precisaríamos investir mais em processos educativos que nos permitissem problematizar e desnaturalizar certas verdades e crenças, possibilitando-nos pensar e viver, de forma valorizada, diferentes configurações e arranjos sociais. Envolver-se politicamente com esse debate pode significar a construção de um currículo que se proponha a investigar questões sociais e culturais mais amplas, dando lugar à curiosidade, à investigação e à dúvida dos/as estudantes, como indivíduos participativos.

Ao deixarmos de levar em conta a variabilidade e a dinâmica dos significados sociais que estão envolvidos nas dimensões de adoecimento e saúde e ao privilegiarmos abordagens educativas que enfatizam uma perspectiva de responsabilização e culpabilização do indivíduo pelo seu problema, estaremos simplificando e reduzindo a complexidade que envolve os processos de vulnerabilização dos/as jovens, bem como deixando de produzir estratégias educativas de controle, prevenção da saúde e de desnaturalização de certos comportamentos sexuais e de gênero hegemônicos e estratificados. Entendemos que olhar criticamente para as propostas vigentes de educação pode significar a análise que circunscreve tanto a formulação dos projetos educativos como a vigilância com a linguagem, no que se refere a localizar as crenças e pressupostos, tomados como legítimos e que embasam determinados conhecimentos. 
E, nesse movimento, podemos ainda nos indagar: Será que estamos aprofundando os sentidos e significados dados aos sujeitos envolvidos naquele contexto social a fim de buscar estabelecer formas de interlocução e de diálogo? Será que estamos buscando alguma aproximação entre os discursos técnicos e os saberes e vivências daquele grupo específico? Estamos atentos para os processos de socialização que incidem na essencialização daquilo que se define como sendo "próprio do homem" e "próprio da mulher"?

Cabe salientar que atuar no campo da educação e se permitir confrontar/articular com o não-homogêneo, o multifacetado e o provisório pode dar lugar à expressão de conflitos, tensões, contradições, sentimentos e compreensões capazes de re-formular e re-criar estratégias didáticopedagógicas no sentido de pluralizar os meios de resolução e enfrentamento das questões que envolvem a relação entre gênero, sexualidade, corpo e prazer. Como já enfatizamos, seria necessário reconhecer que essas dimensões são muito pouco problematizadas e trabalhadas no contexto das escolas e, quando o são, isso é feito em um tom prescritivo, individualizante, normativo e de culpabilização, que explora muito pouco as implicações disso sobre as nossas escolhas ou sobre a falta delas. Talvez não possamos dar conta dessas limitações mesmo com a adoção do referencial da vulnerabilidade, pois, como disse José Ricardo Ayres, "se o HIV fosse transmitido pelo consumo de jiló, provavelmente não teria se tornado uma epidemia. O problema é que uma de suas principais vias de transmissão é o sexo, e porque fazer sexo é muito bom, muita gente o faz e, portanto, o grau de transmissão é muito maior". ${ }^{4}$

Desafios como o proposto neste texto demandam que sejamos capazes de fazer outras perguntas, de inverter as perguntas que

\footnotetext{
4 Em uma aula ministrada no mês de maio de 2007, no curso de Pós-Graduação em Educação da UFRGS, como parte da disciplina "Vulnerabilidade e Gênero: questões para pesquisa em educação e saúde", ministrada pela professora Dagmar E. Meyer.
} 
comumente nos fazemos e de olhar as mesmas coisas de diferentes pontos de vista, o que, necessariamente, transforma-as em coisas diferentes. O referencial da vulnerabilidade pode contribuir muito para a inversão dessas perguntas e olhares e para a renovação de práticas de educação e de saúde em geral e, particularmente, para aquelas que requerem a compreensão e a intervenção em relações de gênero e de sexualidade, como é o caso da prevenção ao HIV/AIDS. Isso porque, segundo Dagmar E. Meyer et al. (2006), ele implica a busca de um novo horizonte para situar e articular essas e outras questões no campo da educação em saúde, trazendo-as para o campo da cultura e da significação, para o mundo dos sujeitos, no qual as relações e as práticas ganham sentidos singulares.

\section{REFERÊNCIAS}

AYRES, José Ricardo; FRANÇA-JUNIOR, Ivan; CALAZANS, Gabriela Junqueira; SALLETI FILHO, Haraldo César. O conceito de vulnerabilidade e as práticas de saúde: novas perspectivas e desafios; In: CZERESNIA, Dina (Org.). Promoção da saúde: conceitos, reflexões, tendências. Rio de Janeiro: Fiocruz, 2003.

DELOR, François. HUBERT, Michel. Revisiting the concept of "vulnerability". Social Science \& Medicine, n. 50, 2000.

LOURO, Guacira Lopes. Gênero, sexualidade e educação: uma perspectiva pós-estruturalista. Petrópolis: Vozes, 1997.

LOURO, Guacira Lopes. Pedagogias da sexualidade. In: LOURO, G. L. (Org.). O corpo educado. Belo Horizonte: Autêntica, 1999.

LOYOLA, Maria Andréa. Sexualidade e medicina: a revolução do século XX. Cad. Saúde Pública, Rio de Janeiro, v. 19, n. 4, jul./ago. 2003.

MEYER, Dagmar E. E. e Cols. Você aprende. A gente ensina? Interrogando relações entre educação e saúde desde a perspectiva da vulnerabilidade. 
Cadernos de Saúde Pública, Rio de Janeiro, v. 22, n. 6, jun. 2006.

MUCHEMBLED, Robert. O orgasmo e o ocidente: uma história do prazer do século XVI a nossos dias. São Paulo: Martins Fontes, 2007.

WEEKS, Jeffrey. O corpo e a sexualidade. In: LOURO, G. L. (Org.). O corpo educado. Belo Horizonte: Autêntica, 1999.

Recebimento: 09/06/2007

Aprovação: 20/08/2007

\section{Contato:}

Dagmar E. Estermann Meyer

Av. Paulo Gama, s/no 12-201

Bairro Bonfim - Porto Alegre

Cep: 90046-900 - RS

dagmarmeyer@yahoo.com.br 